\title{
Em busca da especificidade da influência francesa na análise organizacional no Brasil
}

\author{
Roberto C. Fachin* \\ Neusa Rolita Cavedon**
}

\section{Resumo}

A literatura em administração produzida no Brasil apresenta forte influência da literatura americana, segundo estudos anteriores de acadêmicos brasileiros. Não foram identificados estudos sobre a influência dos países francófonos, particularmente França e Canadá (Québec), na academia brasileira. 0 trabalho pretende suprir a lacuna quanto à influência desses países, analisada a partir de publicações feitas em periódicos e nos encontros nacionais de administração (Enanpads) dos períodos 1995-99 e 2000-01. Especula-se também quanto à especificidade dessa influência, ou seja, em que áreas ela se manifesta mais detidamente, a julgar pelos autores mais citados. Procede-se também uma comparação da influência dos países francófonos na área de Administração e em outros campos do conhecimento (literatura, filosofia, moda, religião), tentando estabelecer ligações com a maneira' francesa' de ver 0 mundo.

Palavras-chave: Literatura, influência, administração

\begin{abstract}
According to Brazilian academic studies, American literature has strongly influenced Brazilian literature on management. Studies about the influence from French speaking countries, specially France and Canada (Québec), on Brazilian academy were not identified. This paper aims to fill this blank, demonstrating the influence from these countries. It considered periodicals and national meetings on management in Brazil (ENAMPADs) from 1995 to 1999 and during 2000/01. We also analyze the specificity of such influence, which means trying to understand in which areas it is more evident. The data were put in a comparative way, since there are evidences about French speaking influence on other areas (literature, philosophy, fashion, religion), trying to establish links with the 'French' way of seeing the world.
\end{abstract}

Keywords: literature; influence; management

\section{Introdução}

Em diferentes eventos e publicações, acadêmicos brasileiros investigaram a nacionalidade dos autores referenciados em análise organizacional no Brasil (VERGARA e CARVALHO, 1995; VERGARA e PINTO, 2000), sobre o conhecimento anglo-saxão na análise organizacional (RODRIGUES, 1997; RODRIGUES e CARRIERI, 2000), e sobre a evolução, importância e qualidade do conhecimento produzido no Brasil (MACHADO-DA-SILVA, CUNHA e AMBONI, 1990; BERTERO e KEINERT, 1994; BERTERO, CALDAS e WOOD Jr., 1998). Como traço comum nas diferentes publicações constata-se a relevância da produção de língua inglesa, refletida na literatura referenciada pelos autores brasileiros. No artigo de Vergara e Carvalho Jr. em que é analisada a nacionalidade dos autores referenciados, é constatada a predominância da bibliografia americana, seguida, a uma grande distância, das bibliografias inglesa e francesa. Supõe-se que tal predominância ocorra mais por ser um conhecimento legitimado no circuito internacional do que pela capacidade de melhor explicar os problemas investigados. Assim, nosso entendimento é de que parece faltar uma análise mais provocativa das diferentes vertentes teóricas que influenciam a produção e a prática brasileira, nos diversos domínios do conhecimento. Nesse sentido, o presente estudo busca refletir sobre a influência dos estudos produzidos em língua francesa - quer os originários da França, quer os originários de outros países

* Doutor em ciências humanas e livre-docente em política e administração pela UFRGS. Professor da PUC-MG e da Fundação Dom Cabral. E-mail: rcfachin@ fdc.org.br.

* Doutora em administração pela UFRGS. Professora da Escola de Administração da UFRGS. E- mail: nrcavedon@ adm.ufrgs.br. 
como o Canadá, da província de Québec (antigamente chamada de Canadá francês). Os autores deste artigo se orientaram pela seguinte pergunta básica: existe influência da francofonia nos estudos e análises organizacionais produzidos no Brasil ? Em caso de que essa influência possa ser de alguma forma identificável, poder-se-ia perquirir: há alguma especificidade na literatura de origem francofônica que seja preciso destacar? Quais são os traços gerais da francofonia que se refletem em outros campos do conhecimento e que reaparecem no campo da administração?

Para explorar essas questões, os autores partiram de uma convicção: a de que as características gerais de uma sociedade e a história de suas inter-relações ajudam a determinar os caminhos de sua produção nos diferentes campos do conhecimento e da influência que ela exerce ou pode exercer em outras sociedades. Ou seja, quem produz um texto ou quem se preocupa com um determinado tema de pesquisa sofre a influência da sociedade em que vive. Da mesma forma, quem aceita receber influxos teóricos ou metodológicos é porque identifica no agente influenciador, aspectos que lhe são particularmente caros ou significativos.

O presente texto desenvolve seu argumento a partir de uma base empírica, ou seja, a partir de um levantamento de autores francófonos identificados no Brasil e presentes nos artigos apresentados nos diferentes ENANPADS, e de uma vivência antropológica e sociológica - com incursões pela literatura, pela moda e pela religião como pontos de ênfase da cultura francesa no Brasil.

\section{0 contexto histórico da introdução do ensino de administração no Brasil}

Os estudos de Vergara e Carvalho (1995) e Vergara e Pinto (2000) apontam o impacto de autores oriundos dos EUA. Certamente, dois aspectos podem ser determinantes nessa influência americana: a história da implantação do ensino de administração no Brasil, assim como o grande número de traduções de livros produzidos originalmente naquele país. Sobre a implantação do ensino de administração no Brasil, observa-se que as preocupações com a administração, como ciência e como prática, apareceram no Brasil nos anos 1930. Entretanto, os cursos regulares de administração (em nível de graduação) foram implantados no país a partir do início da década de 1960. Isso ocorreu em seqüência à intensa qualificação de docentes (atuais ou futuros) em estabelecimentos de ensino dos EUA - com o patrocínio de agências de desenvolvimento norte-americanas em programas de mestrado e, alguns casos, em programas de doutorado. (CNPq, 1982); e estudar nos EUA implicava estudar literatura exclusivamente (ou quase) americana. Quem teve a experiência de ter estudado nos EUA, naquela época, certamente, confirmará que a literatura indicada nas diferentes disciplinas não incluía autores franceses, nem traduzidos.

No Brasil e, no mundo, no entanto, o conhecimento da língua francesa - que se difundia juntamente com uma correspondente influência de sua civilização - teve o seu auge no século XIX e primeira década do século XX, decaindo, em seguida. ${ }^{1}$ Esse decréscimo da influência da língua francesa, e o predomínio da formação em países anglo-saxônicos (especialmente, nos EUA) acabaram por enfatizar a contribuição norte-americana no ensino de administração. Apesar de tal influência, as agências brasileiras de apoio à formação de pessoal para o ensino superior, no entanto, não advogaram que a formação nos EUA fosse hegemônica e, havendo interessados, apoiaram programas de formação em outros países. .A partir de meados da década de 1980, o Ministério das Relações Internacionais de Quebec e a Embaixada do Canadá também passaram a criar oportunidades de formação naquele país. Assim, nos últimos anos, a formação em instituições francesas -e, mais recentemente, em instituições sediadas em Quebec, no Canadá -, aparentemente, explicam o aparecimento de literatura originada nesses países nas publicações brasileiras em administração;

\footnotetext{
${ }^{1}$ Como exemplo, temos o fato de que na década de 1950, no ensino secundário estudava-se em igualdade de condições tanto o francês como o inglês, e havia busca - por exemplo, na Aliança Francesa - de aperfeiçoamento no francês; naquela época, ainda considerada língua universal, a língua da diplomacia. Nessa mesma década, e tendo em vista as oportunidades de estudo nos EUA, o número de alunos em institutos de idiomas de ensino da língua inglesa, como o Instituto Cultural Brasileiro-Norte-Americano e o Instituto de Idiomas Yázigi cresceu, ocasionando quase que um soterramento do conhecimento de língua francesa adquirido na escola secundária e na Aliança Francesa. O ensino da língua francesa passou, de obrigatório a opcional, no ensino secundário; tendo sido eliminado como opção de língua estrangeira no exame de ingresso ao ensino superior (vestibular). Mais tarde, por pressão de professores de francês e de outros setores, voltou a figurar como opção no vestibular, mas de apenas um pequeno número de candidatos.
} 
particularmente; em certos domínios do conhecimento administrativo, constituindo-se uma alternativa importante para evitar o monolitismo norte-americano.

\section{Sobre a influência francesa na cultura brasileira}

Em nossa busca por raízes e especificidade da contribuição e influência da França no campo da administração, embora conscientes dos limites que nos impõe um texto para revista, entendemos de buscar no passado das relações França-Brasil traços de um período em que a França representava uma fonte de influência cultural predominante. Esse período de influência francesa notável, como um modelo, uma projeção cultural muito presente no Brasil foi no século XIX e na primeira metade do século XX. Pode-se mesmo chegar a identificar uma certa francomania, ou seja, uma dependência com relação a certos aspectos da cultura francesa.

Culturas sofrem influências e têm características próprias. Diferenças culturais existentes entre as várias sociedades podem ser exemplificadas através de um texto de DaMatta (1996) que, ao narrar história anedótica que lhe foi contada por um amigo americano, ironiza, embora simplifique, diferenças culturais:

"Vários naúfragos estão à deriva. Um diz para o outro: 'Quer apostar que faço todo o mundo pular no mar?' Seu companheiro obviamente duvida. Uma aposta de alguns milhões o obriga a pôr à prova a idéia. $\mathrm{O}$ apostador diz a um inglês: 'A tradição exige que você se atire' e o inglês pula no mar. No caso do francês, o apelo é para a moda. Para o alemão, fala-se em ordens do chefe, com resultados semelhantes. Sobram um americano e um brasileiro.' Se você mergulhar, há um seguro de US\$2 milhões', diz o apostador para o americano, que pula imediatamente. Em seguida olha para o brasileiro e diz muito sério: 'Sabe, há uma lei que proíbe que se deixe o barco'. Mal termina a frase e o nosso patrício já se encontra no meio do mar...". (DaMATTA, 1996, p.239).

A partir dessa narrativa, DaMatta (1996) reflete sobre o lado rebelde e contraditório do povo brasileiro, muito próximo do modo de ser dos espanhóis. O paradoxo está no fato de ser o Brasil um dos países com um extraordinário volume de leis, que, no entanto, não seriam cumpridas em sua maioria. Segundo esse entendimento, o brasileiro seria regido pela lei das amizades: corre-se todos os riscos em favor de um amigo. ${ }^{2}$ $\mathrm{Na}$ vida social e política, entretanto, ele assume posicionamentos anarquistas e rebeldes tanto quanto sabe ser conformista e submisso. Assim, ele evita se incomodar, motivo pelo qual é capaz de se submeter à injustiça. ${ }^{3}$ Por seu turno, o povo americano, ao contrário (aparentemente), no interior de seu próprio país, parece seguir as leis mais rigidamente, colocando a liberdade e a igualdade (que se originam na Grande Revolução Francesa) como valores maiores a inspirá-lo em sua vida pública. Certamente, o discurso americano é nesse sentido, mesmo quando se institui como 'salvador do mundo' e, em nome das 'práticas democráticas', comete atrocidades.

A história anedótica aqui narrada estabelece o protótipo do francês como alguém condicionado pela moda. Mas é preciso que se note que essa influência específica na moda faz parte de um quadro de influência cultural vasta e generalizada da França - o farol do mundo. ${ }^{4}$

\footnotetext{
${ }^{2}$ Essa visão de leis não cumpridas etc. não é naturalmente exclusividade do Brasil. Em1964, Fred W. Riggs introduzia na literatura administrativa, a reflexão sobre o formalismo como sendo uma características dos países em desenvolvimento (ou prismáticos).

${ }^{3}$ Embora essas considerações sobre o caráter nacional possam sempre ser colocadas em dúvida - principalmente, por ignorarem diferenças existentes no interior de um país -, o crítico literário Roberto Schwarz (1972) consegue demonstrar que a 'estrutura do favor', como nos é confirmada pela formação histórica brasileira, foi o elemento social de base somente compreensível se apelarmos para a noção de sociedade escravagista, que está na origem do Brasil moderno, certamente não muito distante no tempo. A origem do jeitinho brasileiro certamente está aí, a comprovar que a lei pouco efeito tem, pois é sempre possível dar um jeito de escapar de sua aplicação.

${ }^{4}$ No Brasil, por volta de 1830 , os franceses começaram a abrir lojas de moda na cidade do Rio de Janeiro. Além do vestuário, outros artigos tidos como de luxo foram disponibilizados para os consumidores brasileiros. Segundo Durand (1988), as lojas da época tinham, no mínimo, dois sócios: um que se dedicava à loja e à clientela e o outro que realizava constantes viagens para Paris, com o objetivo de se atualizar e repor os estoques. Olhar para Paris (diga-se, França) no setor da moda era mais um olhar ao exterior, presente também na busca da literatura francesa, que já influenciava Portugal (onde a influência cultural francesa também é significativa, tanto quanto a dominação inglesa nas áreas econômica e política. A literatura francesa, na verdade, constituiu-se num espelho para onde os escritores brasileiros (como se verá a seguir) se dirigiam, como, de certa forma, o resto do mundo.
} 
Entretanto, dirigir o olhar para o exterior não significa sempre uma adesão irrestrita, ou uma simples cópia do que se faz no além-mar. O processo é transcultural, onde o elemento exógeno sofre uma adaptação aos gostos e valores locais, sendo assim mais do que uma adesão, mas uma aculturação. Veja-se, por exemplo, o caso da religião. No Brasil, cujo povo é considerado religioso, o espiritismo de Allan Kardec ${ }^{5}$ chegou em meados do século XIX. Os cultos afro-brasileiros populares eram praticados pelas classes socialmente desprivilegiadas desde a última parte do século XIX. As ligações do kardecismo com outros ritos ou religiões tornam-se particularmente interessantes ao estudar-se a umbanda ${ }^{6}$ que representa o sincretismo da religiosidade nativa dos índios e negros brasileiros - com o espiritismo de Allan Kardec. A doutrina cármica do kardecismo é, então, transposta para a umbanda. ${ }^{7}$

Outros exemplos podem ser encontrados no olhar brasileiro para a França. No campo político, pelo menos após a Revolução de 1789, o lema "Liberté, Égalité, Fraternité" repercute no cenário brasileiro e a França aparece, de alguma forma, como o farol da liberdade, inspirando a Inconfidência Mineira (1792), mesmo antes que essa influência aparecesse no cenário norte-americano. No Rio Grande do Sul, o estado mais meridional do Brasil, a Revolução Farroupilha que buscou independência do governo central brasileiro (1835-45) proclamou a República Rio-Grandense que tem como lema de sua bandeira "Liberdade, Igualdade, Humanidade" (ainda presente nos símbolos oficiais do estado) a refletir a influência de Auguste Comte, que também aparece nitidamente nas manifestações dos dirigentes do Partido Republicano Rio-Grandense, que conquistou o poder hegemônico no estado durante anos e influenciou os preceitos da Constituição Rio-Grandense de 1891 (PINTO, 1986). Hoje, o surgimento do Fórum Social Mundial - realizado em Porto Alegre, RS, nos anos de 2001, 2002 e 2003) -, em contraposição ao Fórum Econômico Mundial, tem amplas ramificações em movimentos sociais e grupos franceses de intelectuais de esquerda.

Na filosofia, Arantes (1994) caracteriza a presença e o influxo do modo francês de pensar na filosofia brasileira, particularmente na constituição do Departamento de Filosofia da Universidade de São Paulo. A influência de acadêmicos franceses é amplamente reconhecida na instalação e desenvolvimento da Faculdade de Filosofia, Ciências e Letras de uma das prestigiadas instituições brasileiras de ensino - a Universidade de São Paulo.

$\mathrm{Na}$ arte e na literatura, há inúmeros exemplos. A influência francesa foi particularmente importante no domínio artístico, como, por exemplo, nas "missões" artísticas durante o Império, no século XIX, mesmo que não tenha se dado em todo o país, nem tenha sido permanente. Destaca-se, aqui, apenas algumas influências e absorções. Temos, por exemplo, Balzac que deu vida a personagens que mostraram a vida parisiense cotidiana, refletindo o comportamento de uma época; e Zola, que busca distinguir-se de Balzac, mas "sem deixar de imitá-lo até um certo ponto, quando se propôs a pintar a França do segundo Império, como Balzac o fizera para a Restauração e a Monarquia de Julho, incluindo, contudo, no romance, as classes menos favorecidas de que Balzac não se ocupara. (grifo adicionado) (FARIA, 1988/89, p.129). Assim, a influência do "naturalismo" francês, que a

\footnotetext{
${ }^{5}$ O kardecismo, cujo fundador, Léon-Hippolyte Denizart Rivail, nasceu em Lyon, na França, em 1803. Tendo sido discípulo de Pestalozzi, dedicou-se às atividades educacionais. Em 1854, adota o nome de Allan Kardec - que, segundo consta, foi-lhe revelado por um espírito -, e começa a se dedicar à sistematização da doutrina espírita. Entre os princípios que norteiam o espiritismo está a crença na reencarnação e na evolução dos espíritos, que se dividem em imperfeitos e puros (doutrina cármica).

${ }^{6}$ Não há certeza sobre as origens da umbanda. A forma como é contada a origem da seita em muito se aproxima do que se tem de registros sobre o ocorrido com Allan Kardec. Afirma-se que, no Brasil, no início do século XX, alguns membros da classe média carioca, insatisfeitos com a excessiva intelectualização presente na doutrina espírita, resolveram percorrer terreiros localizados nas favelas do Rio de Janeiro. Nessa época, um desses homens adoeceu e durante a sua enfermidade recebeu o espírito de um índio brasileiro, que lhe imputou a missão de fundar uma religião chamada umbanda. Na França, Allan Kardec, teria recebido esse nome, fruto da revelação de um "espírito de verdade" que se manifestara através de um "medium", ocasião em que lhe foi dito ter sido esse o seu nome no tempo dos druidas.

O primeiro centro de umbanda foi fundado em Niterói, RJ, em 1927. As características dessa religião podem ser resumidas como um culto baseado na possessão pelos espíritos. Os rituais públicos oferecem a possibilidade de serem realizadas "consultas", relacionadas com as mais diferentes aflições; e encaminhamentos são dados, visando à solução desses possíveis problemas.

${ }^{7}$ Traço distintivo entre os cultos afro-brasileiros e a umbanda: os primeiros acionavam práticas bárbaras, como a matança de animais; já a segunda, mais evoluída, vem contrapor-se a essas ritualizações ditas "atrasadas". Os uniformes brancos, usados pelos umbandistas, remetem à noção de assepsia. Conceitos advindos da ciência são absorvidos pela seita que explica o uso, nos rituais, de facas e espadas - elementos mágicos - através da teoria eletrostática. A intelectualização do kardecismo, uma das alegações para a dissidência, reaparece, revelando a origem sincrética, e de certo modo atuando no sentido de legitimar a seita umbandista. Esse exemplo serve para se compreender como aspectos culturais franceses chegaram ao Brasil e de que modo se fundiram às manifestações dos índios e negros, dando origem a uma síntese inovadora.
} 
história da literatura registra como "realismo", aparece nitidamente na obra de Aluísio de Azevedo, "O Cortiço", mais próxima de Zola do que de Balzac.

Como se pode perceber, a realidade sociológica de uma determinada época - englobando a "normalidade" como também, em certos momentos, o inusitado de uma determinada época ou momento histórico - traduz um pouco o modo francês de ver. Foi esse tipo de escritores franceses de que falamos que, tratando dessa problemática, acabaram por se tornar "clássicos". A moral social da "conveniência" e, ao mesmo tempo, indiretamente, sua contestação é que passaram a ser o "moto" de brasileiros que seguiram o passo de seus "pais" da literatura dita "realista". ${ }^{8}$ Esses literatos franceses mostraram a realidade sociológica, os desviantes de suas épocas, e tornaram-se clássicos. Por sua vez, os brasileiros citados, sob a influência francesa, igualmente, encontraram na literatura uma forma de externalizarem o que viam e sentiam diante de um Brasil tão moralista como o era no século XIX. Registre-se aqui que o que se poderia chamar de uma maneira francesa de perceber e "sentir" a realidade continua a influir nos autores brasileiros, o que pode ser identificado quando se ilustra $o$ que aparece hoje como influente no campo da administração. Encontram-se outros paralelismos entre autores franceses e brasileiros. A influência existente é abrangente mas não há condições de se avançar nesse paralelismo dentro dessa comunicação. ${ }^{9}$

Bernd (1996), discutindo essa influência cultural, fala de uma evolução da "francofilia" para a "francofonia"10 desprezando tendência à "francomania", ou seja, "à supervalorização da cultura do outro em detrimento de sua própria cultura" (BERND, 1996, p.33). Uma certa "francomania" ou seja, uma alienação cultural da América Latina, esteve presente, por muito tempo, na sedução das elites latino-americanas do século XIX, pelas idéias em circulação na França, principalmente. Não é outra a interpretação de Vergara e Carvalho Jr. (1995) que atestam que a produção artística e acadêmica dos países terceiro-mundistas apresenta-se extremamente atrelada ao fazer intelectual dos países ditos desenvolvidos. Bernd insiste em afirmar que essa francomania repercute até hoje em "uma certa 'elite' pequeno-burguesa, para quem tudo o que emana de Paris é claramente superior" (1996, p.34). Um concisa referência é feita numa tese de Norma Takeuti ${ }^{11}$ (apud CRISTALDO, 1988/89, p.361) em que são arroladas as imagens usualmente alimentadas pelos bolsistas brasileiros em Paris. Para esses estudantes, a França é: “1) berço da cultura ocidental; 2) eldorado da intelectualidade; 3) pólo irradiante da cultura no mundo; lá, tudo acontece antes; 4) pátria da liberdade; 5) porta-bandeira da democracia; 6) país dos direitos do homem; 7) terra da pluralidade do pensamento aberto; 8) terra do livre pensamento e do laissezfaire; 9) terra para onde você vai e se libera de tudo."

\footnotetext{
${ }^{8}$ Segundo Freyre (1979) era preciso, para Balzac, tratar "tous les effets sociaux de façon à ce que pas une seule situation de la vie, ou une seule physionomie, ou un seul caractère d'homme ou de femme, ou une seule manière de vivre, ou une seule profession, ou un seul secteur social, ni un seul des pays français, ni ne quoi que ce soit concernant l'enfance, la vieillesse, l'âge mûr, la politique, la justice, la guerre... soit oublié".

${ }^{9}$ Um dos escritores mais talentosos da atualidade brasileira, Moacyr Scliar, traduzido em vários idiomas, em depoimento prestado para o número especial (França-Brasil) da revista Travessia, assim descreve sua experiência: "De Molière a Camus, de Rabelais a Marguerite Duras: não se pode falar em literatura sem falar nos escritores franceses. Especialmente no Brasil, onde recebemos tão forte influência da França. Particularmente, sou grato aos professores que me iniciaram nas 'lettres françaises', que liam com voz emocionada, e para embevecidos alunos, os clássicos textos de Victor Hugo ou os versos de Lamartine, alguns dos quais ainda posso repetir de cor. Cresci sob a funda impressão causada pela majestosa beleza do idioma francês. E quando, muitos anos depois de ter saído do colégio, tive um livro traduzido na França, fiquei com a impressão de que, agora sim, estava escrevendo a sério"(Scliar, 1988/89).

${ }^{10}$ Bernd (1996) afirma que a abertura das universidades brasileiras aos estudos francófonos data de aproximadamente 20 anos; pois, até 1975, o ensino do francês era inteiramente centrado na língua, cultura e literatura francesas. A data inicial é 1978, quando o Ministério das Relações Internacionais do Quebec lança um programa de estágio dirigido aos professores (de francês) latino-americanos (três semanas no Quebec). No campo da administração, as datas são quase coincidentes, mas em termos de abertura ao conhecimento produzido na França. Em1980, a CAPES, agência governamental brasileira voltada à melhoria da capacitação do pessoal (fundamentalmente professores) de ensino superior, abriu um programa de cooperação - CAPES/COFECUB - voltado ao incentivo de programas de intercâmbio acadêmico entre instituições francesas e brasileiras, e, no campo da administração. A Universidade Federal do Rio Grande do Sul propôs um programa de cooperação (voltado às subáreas de marketing, finanças, sistemas de informação e gestão de ciência e tecnologia) com as Universidades de Grenoble II e Rennes I, efetivamente implementado a partir de 1983. Antes disso, o intercâmbio com a França, para formação docente, era esporádico, decorrente de iniciativas individuais e apoio ora do Ministério de Relações Exteriores da França, ora da própria CAPES, em programas de balcão. Foi também na década de 1980 que o Quebec começou a aparecer: em 1985, o primeiro autor deste artigo para lá viajou em programa de pós-doutoramento e lá mesmo identificou interesse do Ministério das Relações Internacionais do Quebec em desenvolver programa de bolsa de estudos de pós-graduação para estudantes brasileiros posteriormente firmado com a CAPES.
}

${ }^{11}$ A referência é extraída de um artigo publicado na revista Travessia por Janer Cristaldo. Cristaldo informa que a tese - não divulgada no Brasil - intitulase "Os conflitos de identificação cultural dos estudantes brasileiros na França - a representação mítica da cultura francesa no meio intelectual brasileiro" (Cristaldo, 1988/89). 
Para Pierre Rivas (apud BERND, 1996, p.34-35) a opção pelos paradigmas culturais franceses apresenta-se, na história brasileira, como um gesto de transgressão, provocando a passagem de uma fase inaugural, em que predominava monoliticamente a tradição cultural do colonizador português, para um "salutar dialogismo" representando uma "astúcia da razão tupiniquim" na busca por dar um passo à frente em nosso processo de autonomização (BERND, 1996, p.35). Somente com o Movimento Modernista de 1922 é que essa dependência da França passou a ser criticada, buscando-se sua superação, na busca de um modelo brasileiro, na antropofagia cultural do modernismo. ${ }^{12}$ Segundo Bernd:

A exemplo do índio que devora o inimigo, o absorve e o digere para incorporar suas virtudes, o escritor brasileiro, diante da cultura do outro, teria o mesmo gesto agressivo: devorar a cultura estrangeira para restaurar seu próprio patrimônio cultural"(1996, p.35)

Nas palavras de Bernd (1996, p.36) "a antropofagia vai rejeitar a francomania enquanto admiração beata; a postura antropofágica é a de uma receptividade crítica, logo francófila."

É interessante que se acentue o diálogo que vem sendo estabelecido no campo dos estudos canadenses, por professores desse país em visita ao Brasil. Para um deles, Maximilien Laroche, da Universidade Laval, em Quebec, há elementos comuns para esse diálogo cultural - busca de autonomia, identidade e originalidade. Quando do pronunciamento de tal conferência, ${ }^{13}$ professores brasileiros acentuavam distinções, ao afirmar que não era encontrável no Quebec o caráter antropofágico (agressivo) da literatura brasileira, pois lá a tendência era contrária: atitude defensiva que consiste em não se deixar devorar. (BERND, 1996). Pode-se tomar como confirmação dessa postura o estudo de J. F.Chanlat (1996) a partir do seu título: "Da hegemonia cultural à independência: resistência (o negrito é nosso) francofônica às definições anglo-americanas sobre o que seja conhecimento em administração - o caso de Quebec (1960-1990)". Mas essa linha de raciocínio talvez exija outro texto.

Pode-se dizer, pois, que de uma certa francomania inicial passou-se a uma francofilia; e que no campo da administração, de uma certa francofobia inicial (exceção feita a FAYOL) passou-se, mais recentemente, a um certo apreço pela francofonia, não só entre os brasileiros estudando na França, mas, principalmente, a partir do maior intercâmbio com a região de Quebec.

\section{A americanomania e a francofonia no campo da administração}

A partir da década de 1960, pode-se identificar a presença de uma americanomania, com o deslumbramento pelo desenvolvimento, pela preocupação (do governo) com o "saber fazer", dando-se ênfase ao tecnicismo dos EUA. A crítica tinha sido banida do cenário brasileiro, e o idioma francês começava a ser desprezado pelos jovens que passaram a investir no conhecimento da língua inglesa. O modelo americano de vida é a referência. E essa referência passa a ser dominante.

No entanto, com o tempo, busca-se um novo espelho. Particularmente com o fim do período discricionário, que marcou as décadas de 1960, 1970 e 1980, reacende-se um desejo de um modelo próprio, de uma postura crítica que, em alguns setores da academia provoca um retorno à França e um voltar-se ao pensamento quebequense, por exemplo, onde a influência resultante da proximidade dos EUA e da preocupação típica da latinidade de origem francesa introduz novos temas e abordagens.

Ao olharmos para a administração, verificamos que um bom número de acadêmicos quebequenses e franceses assumem, tal qual na literatura, uma postura de retratar o cotidiano e de denúncia. Nesse ramo do conhecimento, a crítica recai sobre o sistema de trabalho capitalista; os recônditos das fábricas e dos escritórios são descortinados; os desviantes - trabalhadores com sua saúde mental abalada pelo modo de produção entram em cena; descortina-se a realidade não de personagens da ficção, mas do mundo concreto do trabalho.

\footnotetext{
${ }^{12}$ Na mesma linha do que se discute neste estudo, Caldas e Wood Jr. (1999) retomaram a postura antropofágica do Movimento Modernista de 1922 para invocar a necessidade de sua incorporação nos estudos administrativos, no sentido da construção de um pensamento brasileiro sobre o administrar.

${ }^{13}$ Proferida em 1982 na Universidade de São Paulo (BERND, 1996).
} 
Uma parte da academia brasileira se entusiasma diante desse desnudamento e resolve adotar linhas de pesquisas semelhantes. Temas como inveja, afetividade, loucura e questões de gênero aparecem como problemas de pesquisa. Jean-François Chanlat, francês, radicado no Canadá, ${ }^{14}$ apesar de crítico e renovador de temáticas, consegue publicar no Brasil, textos, por vezes, reunindo vários autores, apresentando linguagem às vezes próxima da brasileira. Ao abordar temáticas consideradas cruciais para o fazer administrativo, consegue fazê-lo desprovido de radicalismos excessivos, bem ao gosto da tendência brasileira de evitar confrontos, usando a sutileza do "jeitinho". Por seu turno, o francês Christophe Dejours, com seus estudos sobre psicopatologia do trabalho, revela a psique dos trabalhadores, as patologias decorrentes da opressão, do controle e dos longos turnos de trabalho. O tom de sua crítica, mais acirrada, parece agradar estudiosos brasileiros que, apoiando-se no referencial de Dejours, partem para captar o contexto organizacional em sua essência; deixando de lado a visão behaviorista (tão cara a autores americanos) em prol da interpretação de cunho psicanalítico. Mencionamos tais autores pois é neles que identificamos maior influência, pelo número de citações encontradas nos textos pesquisados.

À guisa de exemplificação dessa influência, veja-se o trabalho de Seligmann Silva, publicado na Revista de Administração de Empresas (SILVA, 1991). Através da descrição de um caso, em que um trabalhador relata a sua trajetória, a autora revela a interface entre saúde mental e trabalho, ${ }^{15}$ a partir da visão dejouriana do sofrimento e prazer no trabalho transposta para a realidade brasileira.

Concluindo, pode-se dizer que a crítica, elaborada de modo refinado por quebequenses e franceses, dá o tom para parte da intelectualidade brasileira.

\section{A produção intelectual brasileira no campo da administração e a influência francofônica ${ }^{16}$}

Como já dito anteriormente, a influência francesa no Brasil foi (e é) significativa. O ponto principal deste texto é, no entanto, identificar a frequiência, a qualidade e a especificidade dessa influência no campo da administração.

Quais os paradigmas ou propostas de origem francófona que têm relevância competitiva no contexto do conhecimento em administração? Que outros aspectos da maneira francesa de fazer ciência e de ver o mundo têm tido presença no contexto brasileiro? Bertero, Caldas e Wood Jr. (1998) reconhecem que "diferentemente de outras áreas das ciências sociais e humanas, a produção de conhecimento em administração é geralmente aberta a diferentes paradigmas e diferentes abordagens metodológicas" (apud FACHIN e RODRIGUES, 1999, p.101). Rodrigues (1997) acentua preferência pela metodologia qualitativa como também identifica que, especialmente a partir de 1995, estudos com abordagem crítica são tão freqüentes como os de perspectiva mais pragmática.

\footnotetext{
${ }^{14}$ Hoje, de volta à França (Université de Paris-Dauphine).

${ }^{15} \mathrm{O}$ trabalhador, sr. Júlio, 55 anos, reside em São Paulo, em moradia própria. Natural do interior de Santa Catarina, dedicou-se, a partir dos 13 anos, às atividades do campo em uma fazenda onde seu pai era empregado. Depois de servir ao Exército, voltou para a fazenda. Todavia, aos 24 anos, resolve mudar para São Paulo, pensando em encontrar um serviço no qual pudesse progredir. Primeiramente, trabalhou em uma padaria, depois foi para uma tecelagem. Neste último emprego, por erro de um colega, teve três dedos da mão esquerda decepados. Fica no seguro por seis meses. Ao retornar para a tecelagem, é despedido. Durante seis meses fica desempregado, período em que se dedica a fazer um curso de mecânica. É admitido em uma siderúrgica. Trabalha em diferentes atividades, faz um curso por correspondência e é promovido a mecânico de manutenção dos compressores da siderúrgica. Prometemlhe a chefia e um grande ordenado, mas não cumprem com o combinado. O ambiente de trabalho é insuportável devido ao calor e à falta de equipamentos de segurança. Isso, associado à responsabilidade pela manutenção de um equipamento que representava risco de vida iminente, começou a desequilibrar a psique do sr. Júlio. Problemas com o sono e irritabilidade começaram a ser freqüentes. Pai de quatro filhos, mostrava-se irritadiço quando as crianças colocavam o som em volume um pouco mais alto. Sentia dores de cabeça, passou a ter desmaios, crises de violência contra familiares. Dirigia-se, então, ao convênio médico da empresa, era medicado e liberado para voltar ao trabalho. A empresa negava-se a comprar peças novas para que a manutenção fosse executada com qualidade, o que preocupava o sr. Júlio, além de implicar retrabalho, pois a durabilidade das peças recondicionadas era extremamente precária. Os transtornos psíquicos agravam-se a ponto do sr. Júlio agredir uma de suas filhas com uma faca. A crise de nervos mais aguda ocorre após 47 horas ininterruptas de trabalho, quando um desmaio o leva à internação e uma sensação de medo apodera-se do operário, que então necessita do auxílio de um familiar para locomover-se. Durante os anos de trabalho na siderúrgica, o sentimento de não ser tratado com reconhecimento e de ter que calar diante das irregularidades foram se acumulando até o momento em que se tornaram agudos, sob a forma de distúrbios psíquicos.

${ }^{16}$ Como o leitor já deve ter percebido, identificamos o termo francofonia com os países de língua francesa e, na prática com a França e o Quebec (ou Canadá francês, como antigamente se chamava).
} 
Fachin e Rodrigues (1999) ressaltam da obra de Bertero \& Keinert (1994) o destaque dado à importância de conceitos, teorias e variáveis das ciências sociais para a análise organizacional, indicando que, no Brasil, a tradição das ciências sociais, diferentemente da norte-americana, não é funcionalista, tendo ocorrido ampla "adoção do marxismo para interpretação da realidade social" e não havendo "vínculo tão importante entre análise organizacional e funcionalismo, característico de grande parte da produção norte-americana e também inglesa" (BERTERO e KEINERT, 1994, p.82)

O estudo de Vergara e Carvalho Jr.(1995) efetuou a contagem das diversas referências bibliográficas (ainda que do mesmo autor) e não do número de autores. A coleta de dados foi acrescida de um questionário enviado a pesquisadores brasileiros que se utilizaram dessas referências. Os autores da pesquisa perceberam acréscimo significativo da produção proveniente do Canadá, ${ }^{17}$ nos últimos anos do levantamento. Dentre as justificativas dos pesquisadores brasileiros para o uso do referencial canadense tem-se: a descoberta recente dos referidos autores, a importância científica dos mesmos, o grande número de publicações existentes. Curiosamente, esses autores não atribuem a adequação das teorias canadenses à realidade brasileira como uma das primeiras prerrogativas para a escolha. Todavia, arriscaríamos afirmar que parece ser a concordância com o modo de articular o pensamento interpretativo e a ideologia subjacente que movem o pesquisador em busca de um referencial em detrimento de outro. Talvez isso ocorra de modo inconsciente ou os pesquisadores tenham resolvido calcar suas respostas em uma base mais científica, omitindo a subjetividade.

Buscando atualizar o estudo realizado por Vergara e Carvalho Jr. (1995), que abrangia o período 1989-93, Vergara e Pinto (2000) estudaram o período 1994-98. Os dados registram que, do total, 33,62\% correspondiam a autores norte-americanos (EUA), 30,90\% a autores brasileiros, 6,97\% a autores ingleses, 5,17\% a autores franceses e 2,39\% a autores canadenses (o estudo não indica se de origem inglesa ou francofônica). Não houve modificação sensível entre os dados registrados pelos dois estudos supracitados (VERGARA e CARVALHO Jr., 1995; e VERGARA e PINTO, 2000).

Os autores deste artigo procuraram estudar a influência francófona na produção científica da administração no Brasil, embora sem a mesmo amplitude dos estudos de Vergara e Pinto (2000) ou de Vergara e Carvalho Jr. (1995). Foram analisados, exclusivamente, os artigos publicados nos anais do congresso de maior relevância da área no país, o Encontro Anual da Associação Nacional dos Programas de Pós-Graduação em Administração (ENANPAD), privilegiando duas áreas temáticas: organizações e recursos humanos. $\mathrm{O}$ estudo foi empreendido em duas etapas, a primeira compreendeu o período que vai de 1995 a 1999 e a segunda etapa abrangeu o período de 2000 a 2001. Optou-se pelo levantamento da bibliografia utilizada e não pelo número de citações. Foi observado que entre os autores mais referenciados, há uma marcante presença daqueles que já tiveram suas obras traduzidas para o português.

Em termos quantitativos, a primeira fase do levantamento destacou os nomes de Christophe Dejours e de JeanFrançois Chanlat, francês e quebequense, respectivamente. Numa bibliografia que relacionou 235 autores, o nome Dejours aparece 39 vezes; enquanto que J. F. Chanlat tem o seu nome repetido 26 vezes. Em ordem decrescente, os 11 autores com presença expressiva na bibliografia foram:

Período de 1995 a 1999:

- DEJOURS, C. (39 referências);

- CHANLAT, J. F. (26 referências);

- PAGÈS, M. et alii (22 referências);

- ENRIQUEZ, E. (19 referências);

- AKTOUF, O. (16 referências);

- THÉVENET, M. (14 referências);

\footnotetext{
${ }^{17}$ Não registram se os autores canadenses são francófonos ou anglófonos. Considerando-se o propósito deste estudo, a distinção é importante, quando mais não seja, pela presença de Henry Mintzberg - muito citado no Brasil - entre os autores canadenses.
} 
- BOURDIEU, P. (12 referências);

- MOSCAROLA, J. (10 referências);

- CORIAT, B. (8 referências);

- BARDIN, L. (7 referências);

- GAULEJAC (7 referências).

A segunda fase do levantamento consolidou a presença de Jean François Chanlat como o autor mais referenciado dos últimos dois anos, nos artigos apresentados nos ENANPADs. Dos 150 autores referenciados nesse período destacaram-se:

Período de 2000 a 2001:

- CHANLAT, Jean-François (33 referências);

- FOUCAULT, M. (25 referências);

- DEJOURS, C. (24 referências);

- BOURDIEU, P. (17 referências);

- PAGÈS, M. et alii (15 referências);

- MORIN, E. (15 referências);

- ENRIQUEZ, E. (12 referências);

- BARDIN, L. (12 referências);

- THÉVENET, M. (8 referências);

- AKTOUF, O. (8 referências).

Outros autores de origem francofônica foram referenciados, nas duas fases da pesquisa, porém, sem a recorrência significativa dos anteriormente mencionados. Há um ponto que, talvez, possa ser considerado; tratase dos modismos, que no fundo é herança de um valor francês no Brasil. Certos autores aparecem em determinadas épocas por força da moda. A academia também se pauta por esse valor; e o desconhecimento de determinado autor tido como um expert do momento é algo condenável, significando ficar à margem da produção considerada como relevante naquele tempo-espaço.

Dentro da mesma perspectiva de identificar a influência de literatura estrangeira na produção científica brasileira, Rodrigues e Carrieri (2000) fizeram levantamento dos autores mais citados, nos encontros anuais da ANPAD, nos últimos 10 anos, entre aqueles listados no livro Writers on organizations (PUGH e HICKSON, 1997). De um total de 525 citações, em que o mais citado foi Gareth Morgan com 75 citações, os autores franceses mencionados foram Crozier (com 13 citações) e ainda Fayol, com 8. Os mesmos autores, ao computar citações de autores não considerados no livro de Pugh \& Hickson, identificaram J. F. Chanlat com 26, Aktouf, com 23, Bourdieu com 20, e Pagès com 19.

Um dos autores mais citados no Brasil, J. F. Chanlat, em artigo publicado em 1996, preocupou-se com a especificidade da contribuição da francofonia para a análise organizacional. No texto, acentua que é uma produção que apresenta diversidade e originalidade, praticamente ignorada pelos autores anglo-saxões; merecendo mais atenção do que tem recebido até agora. J. F.Chanlat acentua os primeiros estudos em sociologia industrial e o fato de que grupos oficialmente instituídos não se criaram antes dos anos 1960, quando aparece notavelmente a obra de Michel Crozier. Identificando o campo da análise organizacional como incluindo várias correntes e paradigmas, J. F. Chanlat classifica como as mais notáveis as seguintes vertentes:

- estratégica;

- sociocultural; 
- psicossociológica;

- acionalismo (de Touraine);

- sistêmica;

- sociopolítica;

- antropológica;

- epistemológica.

Se quisermos enquadrar os autores utilizados pelos acadêmicos brasileiros, dentro da amostra que estudamos (considerando veículo de publicação e anos estudados), indicar-se-ia que a contribuição francesa, no Brasil, seria enquadrada nas correntes sociocultural e psicossociológica.

Finalmente, a julgar pelas perspectivas na teorização organizacional, identificadas por Reed (1999) racionalidade, integração, mercado, poder, conhecimento ou justiça - categorizando problemáticas com foco em questões de ordem, consenso, liberdade, dominação, controle, e participação, talvez seja possível identificar como primeira aproximação - a contribuição do pensamento francês às problemáticas de dominação, controle e participação, de uma perspectiva crítica.

\section{Uma conclusão temporária}

Os levantamentos feitos para este artigo e por outros autores indicam uma influência reduzida da contribuição de países francofônicos (especificamente França e a região de Quebec) na análise organizacional feita no Brasil. Vergara e Pinto (2000) chegam, inclusive, a observar uma redução nessa influência nos últimos cinco anos. Essa menor influência é notada, também, em outros setores da intelectualidade brasileira, como demonstrado no início deste artigo.

É patente, no entanto, identificar que a influência francesa (ou francofônica) se expressa seletivamente em certos setores. Na moda, por exemplo, os estilistas franceses ainda aparecem com força. Na área do turismo, a elegância faz parte da busca por turismo na França, particularmente Paris. Na literatura, há ainda considerável grupo de autores franceses que exerceram ou exercem influência nos intelectuais brasileiros, por exemplo: Flaubert, Balzac, Zola, Sartre, Prévert. Quais, então, os temas que seletivamente aparecem nos estudos sobre administração?

Os dados coletados nos encontros anuais da ANPAD dos últimos dois anos indicaram-nos referências bibliográficas de 150 autores. Os mais citados levam-nos a um conjunto de apenas 10 autores (já mencionados). Quais seriam as temáticas dominantes de tais autores? A preocupação com o indivíduo como sujeito dominado nos processos organizacionais, numa abordagem crítica e humanista, transparece em mais de um autor. O poder como elemento de dominação aparece em Pagès, Foucault, Aktouf, Enriquez. A preocupação com a participação como elemento importante nos processos administrativos que se queiram humanos aparece novamente em autores como Aktouf e Enriquez.

Talvez, as raízes da influência francofônica devam ser buscadas, de preferência, em alguns traços característicos do pensamento crítico francês, que aparecem sobejamente em seus filósofos e em alguns críticos do pensamento dominante da administração, mas também no acesso mais fácil (via livros traduzidos) de alguns autores ao público brasileiro. Nesse particular, a presença de certos autores quebequenses é significativa; resultado, provavelmente, de um intercâmbio mais atuante, em especial por parte de tais autores (exemplo: J. F. CHANLAT, como autor e organizador de obras coletivas, e OMAR AKTOUF), culminando em publicações disponíveis em português.

Ao decrescer a influência da cultura francesa (ocasionando redução no estudo e difusão da língua francesa) reduziu-se, em consequiência, o acesso dos brasileiros a textos publicados em francês. Contudo, há uma certa compensação: órgãos governamentais brasileiros (CAPES, por exemplo) ao estimular o intercâmbio acadêmico 
com diferentes países, possibilitaram que brasileiros buscassem doutoramento na França - geralmente, mas não apenas, em áreas como sociologia, filosofia e economia do trabalho -, através de programa entre governos (o CAPES/COFECUB), e no Canadá. Mas, principalmente, o programa HEC-ACDI propiciou, mais recentemente, muitos programas de doutoramento ou de doutorado-sanduíche, em Montreal, Quebec, aumentando o número de doutores em administração com conhecimento específico (e, conseqüentemente, acesso) da língua francesa.

Para um maior avanço nessa tentativa de identificar a influência francesa nos estudos organizacionais e como estes são feitos (e ensinados) no Brasil, seria necessário, entre outros levantamentos e análises, verificar planos de ensino de disciplinas, em que o estudo de autores - não necessariamente referidos em artigos publicados possa identificar outros autores que não os aqui analisados. Mas isso - e outros aspectos que sejam identificados na discussão com outros colegas - é tarefa para um aprofundamento posterior.

De forma ainda parcial, a priori, pode-se afirmar que os pesquisadores brasileiros que se apoiam na bibliografia francofônica o fazem tendo presente questões ideológicas, uma visão crítica, bem como a busca de um aporte teórico que contemple a complementariedade dos saberes e não a visão sob uma única ótica. Vale destacar, igualmente, o refinamento, ou melhor, a sutileza com que são tratados determinadas temáticas; algo que vem ao encontro da forma de agir dos brasileiros, onde o "jeitinho", a "malandragem", a "ambigüidade" são preferíveis ao "autoritarismo", ao "ser caxias", ao "exato".

Concluindo, todos os estudos compulsados e mesmo os levantamentos feitos pelos autores deste texto, indicam a reduzida influência (numérica) de autores franceses ou quebequenses na literatura brasileira de administração. As indicações da diferente gama de influências da francofonia em diferentes setores do conhecimento, como levantado neste artigo, indicam que, particularmente, certas temáticas, certas preocupações só encontram ressonância em obras encontradas em autores da francofonia, ou seja, a influência da francofonia é necessariamente seletiva. Pretender que uma cultura (da francofonia) cuja tradição de obras na área das ciências sociais é crítica e não pragmática exerça influência em todos os setores da administração é uma ilusão. Fachin e Rodrigues (1999, p.101) registraram que Rodrigues (1997) afirmou o declínio, no Brasil, "da influência dos estudos organizacionais tradicionais oriundos da vertente americana e britânica, e que as mudanças enfrentadas pelo país (tais como abertura de mercado, a presença cada vez mais forte do capital estrangeiro, em suma, os passos que nos levam ao termo 'globalização') têm provocado novos temas (vantagens competitivas, métodos de produção baseados nas experiências japonesas, inovação e aprendizagem organizacional) bem como novos relacionamentos de pesquisa e que ainda assim, et pour cause, os estudos tradicionais têm sido incapazes de proporcionar as explicações esperadas e as soluções para os problemas enfrentados pela sociedade brasileira de hoje." Um tema recorrente nas discussões acerca da cultura organizacional é o da identidade diante da diversidade; e para que possamos dar conta dessa dicotomia - que é ao mesmo tempo antagônica e complementar - torna-se imperiosa a busca de estudos de influência francofônica, de cunho interpretativo, onde o desvendamento do simbólico anteceda a toda e qualquer ação administrativa, servindo, assim, de pano de fundo para uma prática no campo da administração que reconheça o ser humano como um ser simbólico, que precisa de mitos, ritos, símbolos e magia para viver.

Em consequiência, há que buscar, na francofonia, o influxo daquela produção acadêmica que, com embasamento em certas áreas seletivas do conhecimento, traduzem o pensamento crítico francês tão caro aos intelectuais brasileiros de todos os setores. E, sem dúvida, a disponibilidade de tais obras em língua portuguesa, representa substancial acréscimo às possibilidades de leitura dos acadêmicos brasileiros que não tiveram formação pós-graduada na França ou no Quebec. 


\section{Referências bibliográficas}

ARANTES, P. E. Um departamento francês de ultramar: estudos sobre a formação da cultura filosófica uspiana. Rio de Janeiro: Paz e Terra, 1994.

BERND, Z. Brasil/França: uma relação difratada. Artexto. Rio Grande (RS), v.7, p.33-40, 1996.

BERTERO, C. O.; CALDAS, M. P.; WOOD JR., T. Critérios de avaliação da produção científica em administração no Brasil. São Paulo: NPP/EAESP, 1998. (Relatório de pesquisa).

BERTERO, C. O.; KEINERT, T. M. M. A evolução da produção brasileira em análise organizacional a partir dos artigos publicados pela RAE no período de 1961-93. Revista de Administração de Empresas, v.34, n.3, p.81-90, 1994.

BETHLEM, A. Gerência à brasileira. São Paulo: McGraw Hill, 1989.

BROWN, D. 0 papel histórico da classe média na umbanda. Religião e Sociedade, v.1 n.1, p.31-42, 1977.

CALDAS, M.; WOOD JR., T. Antropofagia organizacional. In: CALDAS, M.; WOOD JR., T. Transformação e realidade organizacional. São Paulo: Atlas, 1999.

CAVEDON, N. R. A cultura brasileira e a questão da transferência de tecnologia administrativa. Perspectiva Econômica. São Leopoldo, v.25, n.68, p.77-95, jan./mar. 1990.

CHANLAT, J. F. Francophone organizational analysis (1950-1990): an overview. S.d. xerox

. From cultural imperialism to independence: francophone resistance to anglo- american definitions of management knowledge in Québec. In: CLEGG, S.; PALMER, G.(Eds.). The politics of management knowledge. London: Sage, 1996. cap.7, p.121-140.

CLEGG, S.; HARDY, C.; NORD, W. (Orgs. edição original); CALDAS, M.; FACHIN, R.; FISCHER, T. (Orgs. edição brasileira). Handbook de estudos organizacionais - modelos de análise e novas questões em estudos organizacionais. São Paulo: Atlas, 1999. v.1.

CNPq. (Brasil) Administração e perspectivas 1982 - área: administração. Brasília, 1982.

CRISTALDO, J. Au bord'elle. Travessia, UFSC, ns.16/17/18, p.356-364, 1988/89.

DAMATTA, R. Torre de babel. Rio de Janeiro: Rocco, 1996.

DURAND, J. C. Moda, luxo, economia. São Paulo: Babel Cultural, 1988.

FACHIN, R. C. Transferência de tecnologia administrativa, o ensino de graduação em administração e o papel da pós-graduação. Revista de Administração, IA/FEA/USP, v.25, n.4, p.22-28, out./dez. 1990.

FACHIN, R. C.; RODRIGUES, S. B. Nota técnica: teorizando sobre organizações - vaidades ou pontos de vista? In: CLEGG, S. R.; HARDY, C.; NORD. W. R. (Orgs. edição original); CALDAS, M.; FACHIN, R.; FISCHER, T. (Orgs. edição brasileira). Handbook de estudos organizacionais --modelos de análise e novas questões em estudos organizacionais. São Paulo: Atlas, 1999. v.1, p.99-104.

FARIA, N. O naturalismo e o(s) naturalismo(s) no Brasil. Travessia, UFSC. ns.16/17/18, p.124-147, 1988/89.

FREYRE, G. Heróis e vilões no romance brasileiro. São Paulo: Cultrix/USP, 1979.

FRY, P. H.; HOWE, G. N. Duas respostas à aflição: umbanda e pentecostalismo. In: Debate e Crítica, n.6, p.75-94, 1975.

MACHADO-DA-SILVA, C.; CUNHA, V. C.; AMBONI, N. Organizações: o estado da arte da produção acadêmica no Brasil. In: ENANPAD, $14 .$, Belo Horizonte, 1990. Anais... Belo Horizonte: ANPAD, 1990. v.6, p.11-28.

M OTTA, F. C. P.; CALDAS, M. (Org.). Cultura organizacional e cultura brasileira. São Paulo: Atlas, 1997.

ORTIZ, R. A morte branca do feiticeiro negro. Religião e Sociedade, v.1 n.1, p.43-50, 1977.

PINTO, C. R. J. Positivismo. Um projeto político alternativo_(RS:1889-1930). Porto Alegre: L\& PM Editores, 1986.

PUGH, D.S.; HICKSON, D. J. Writers on organizations. London: Sage, 1997.

REED, M. Teorização organizacional: um campo historicamente contestado. In: CLEGG, S. R.; HARDY, C.; NORD. W. R. (Org. edição original); CALDAS, M.; FACHIN, R.; FISCHER, T. (Org. edição brasileira). Handbook de estudos organizacionais -- modelos de análise e novas questões em estudos organizacionais. São Paulo: Atlas, 1999. v.1, p.61-98.

RIGGS, F. W. Administration in developing countries- the theory of prismatic society. New York: Houghton Mifflin, 1964.

RODRIGUES, S. B. Organization studies: Anglo-Saxon knowledge in Brazil. Ensaios de Administração, UFM G, Belo Horizonte, n.002, 1997.

RODRIGUES, S. B.; CARRIERI, A. P. A tradição anglo- saxônica nos estudos organizacionais brasileiros. In: I Encontro Nacional de Estudos Organizacionais (ENEO), Curitiba, Paraná: ANPAD/CEPPAD- UFPR, junho 2000. CD-ROM.

SCLIAR, M. Depoimento. Travessia, UFSC. ns. 16/17/18, p.314, 1988/89. 
SILVA, E. S. A inter-relação trabalho- saúde mental. Revista de Administração de Empresas, v. 31, n.4192.

SCHWARZ, Roberto. Dépendance nationale, déplacement d'idéologies, littérature, L'Homme et la Société, n.26, Paris, Anthropos, 1972.

VERGARA, S. C.; CARVALHO, D. D. Nacionalidade dos autores referenciados na literatura brasileira sobre organizações. In: ENANPAD, 19. João Pessoa-PB, 1995. Anais... João Pessoa: ANPAD, 1995 v.6, p.169-188.

VERGARA, S. C.; PINTO, M. C. S. Nacionalidade das referências teóricas em análise organizacional: um estudo das nacionalidades dos autores referenciados na literatura brasileira. In: I Encontro Nacional de Estudos Organizacionais (ENEO), Curitiba, Paraná: ANPAD/CEPPAD-UFPR., junho 2000. CD-ROM. 